\title{
UPGRADE NO DIREITO DE ARREPENDIMENTO VIRTUAL: PROJETOS DE LEI 281/2012, 283/2012 E 4678/2016
}

\section{UPGRADE IN THE VIRTUAL COOLING-OFF RULE: BILL 281/2012, 283/2012 AND 4678/2016}

\author{
${ }^{1}$ Kelly de Souza Barbosa \\ ${ }^{2}$ Adalberto Simão Filho
}

\section{RESUMO}

O capitalismo voraz contra os consumidores é contido pela legislação consumerista que estabelece direitos como o do arrependimento. $\mathrm{O}$ consumidor arrependido da aquisição de um produto ou serviço do qual não teve acesso físico, contratado à distância, poderá no prazo legal retornar ao status a quo. Com o aumento das contratações eletrônicas e do marketing agressivo, esse direito tornou-se mais evidente, máxime pelas aquisições desastrosas ou precipitadas. Utilizando o método dedutivo, com pesquisa descritiva, bibliográfica e documental, analisouse os Projetos de Lei 281/2012, 283/2012 e 4678/2016 que visam atualizar e instrumentalizar o exercício do direito de arrependimento virtual.

Palavras-chaves: Consumidor; Comércio Eletrônico; Direito de Arrependimento; Projetos de Lei.

\begin{abstract}
The voracious capitalism against consumers is contained by consumerist legislation establishing rights such as cooling-off rule. The repentant consumer purchasing a product or service which had no physical access, contracted at the distance, can the legal term return to the status quo. With the increase of electronic contracting and aggressive marketing, that right has become more evident, celing by acquisitions disastrous or hasty. Using the deductive method, descriptive, bibliographical and documentary research, we analyzed the Bills 281/2012, 283/2012 and 4678/2016 which aim to update and equip the exercise of virtual cooling-off rule.
\end{abstract}

Keywords: Consumer; E-commerce; Cooling-off Rule; Bill.

\footnotetext{
${ }^{1}$ Mestranda em Direitos Coletivos e Cidadania pela Universidade de Ribeirão Preto - UNAERP, São Paulo (Brasil). E-mail: kelly_sbarbosa@hotmail.com

${ }^{2}$ Pós-Doutor pela Universidade de Coimbra - UC, Coimbra (Portugal). Professor pela Universidade de Ribeirão Preto - UNAERP, São Paulo (Brasil). E-mail: adalbertosimao@uol.com.br
} 


\section{INTRODUÇÃO}

Não obstante os avanços sentidos no sistema protetivo da relação de consumo, após a edição da Constituição Federal, ainda é fato que o desequilíbrio entre o consumidor e o fornecedor se faz sentir sobremaneira em relações virtuais.

Mesmo com as diretrizes do Código de Defesa do Consumidor na busca de uma resposta estatal para o restabelecimento horizontal destas relações econômicas, há grandes impasses, precipuamente, quanto ao exercício do direito de arrependimento, sobretudo na contemporaneidade.

O advento da sociedade da informação numa Era posterior a pós-modernidade (século $\mathrm{XX)}$ causou metamorfoses sociais, econômicas e jurídicas, interferindo na forma como as pessoas se inter-relacionam, trabalham e contratam. A economia informacional rompeu velhos paradigmas e o conhecimento tecnológico foi supervalorizado no atual estabelecimento empresarial virtual.

A globalização, os avanços tecnológicos e a universalização da internet propiciaram o surgimento do e-commerce e e-business, permitindo a contratação célere e instantânea em ambiente exclusivamente digital.

Haja vista que o consumidor virtual não tem contato direto com o produto ou serviço oferecido constantemente pelo fornecedor, muitas vezes ele acaba contratando algo por impulso, e após um momento de reflexão verifica que não lhe era vantajoso, ou pior, não foi capaz de atender suas expectativas.

Nestes casos, o direito de arrependimento deve ser exercido pelo consumidor, consoante a lei e os princípios. No entanto, ainda há mistificação e dificuldades na efetivação deste direito no âmbito virtual, sendo mister um upgrade na legislação consumerista brasileira.

Os Projetos de Lei 281/2012, 283/2012 e 4678/2016 são importantes iniciativas de atualização do direito de arrependimento virtual, pois visam adaptar a norma à realidade fática reconhecendo a vulnerabilidade do consumidor, a necessidade de tutela específica e de instrumentalização do exercício desse direito.

Objetivando explicitar as propostas legislativas para a alteração do Código de Defesa do Consumidor quanto ao direito de arrependimento nos contratos eletrônicos, o presente artigo foi desenvolvido em três capítulos, pelo método dedutivo, com pesquisa descritiva aliada ao arcabouço bibliográfico e documental (legislação e jurisprudência). 
No primeiro capítulo foi realizada uma digressão sobre os direitos dos consumidores, da promulgação do Código de Defesa do Consumidor brasileiro e da atual normatização do direito de arrependimento. Avançou-se no segundo capítulo para a contextualização da Revolução Informacional, enfocando as relações comerciais em ambiente virtual e a legislação específica sobre contratos eletrônicos. E, por fim, no terceiro capítulo foram analisadas as diretrizes propostas nos Projetos de Lei 281/2012, 283/2012 e 4678/2016 para o exercício do direito de arrependimento virtual.

A inércia legislativa para a proteção consumerista é rompida com as Propostas de Lei em tela. Todavia, para que elas realmente produzam os efeitos pretendidos e reequilibrem a relação fornecedor-consumidor virtual, a tramitação deve seguir e em tempo hábil culminar nas aprovações, o que não se verificou.

\section{CÓDIGO DE DEFESA DO CONSUMIDOR E O DIREITO DE ARREPENDIMENTO}

O Estado Social desperta o viés de salvaguarda da massa populacional oprimida pelo capitalismo feroz corporificado pelas indústrias organizadas pelos burgueses - ou melhor dizendo, pelos empresários -, durante a Revolução Industrial inglesa (fim do século XIX e início do século XX) e a I Guerra Mundial (1914-1918).

Os direitos sociais são reconhecidos, assim como, a necessidade da intervenção estatal para a consubstanciação dessas prerrogativas pela população. Elevados ao patamar de direitos fundamentais, os direitos sociais foram constitucionalizados primeiramente pelas constituições mexicana de 1917, alemã de 1919 e brasileira de 1934 .

No rol de direitos sociais estão os direitos humanos do consumidor, com respaldo normativo nacional e internacional. Acerca deste último cenário, a Resolução da Organização das Nações Unidas no 39/248 de 1985 reconhece que “(...) os consumidores muitas vezes enfrentam desequilíbrios em termos econômicos, níveis educacionais e poder de barganha (...)” (tradução nossa) ${ }^{3}$, na relação com o fornecedor.

Segundo Sérgio Resende de Barros [201-?] os direitos dos consumidores são ao mesmo tempo categorial e difuso. Categorial porque ele protege uma categoria social economicamente fragilizada, in casu, os consumidores em relação ao fornecedor, produtor ou

\footnotetext{
${ }^{3}$ Versão original do trecho retirado do item 1 - Objetivos da Resolução no 39/248 da ONU: “(...) recognizing that consumer soften face imbalances in economicterms, educational levels, and bargaining power (...)”. (ONU, 1985, p. 3)
} 
comerciante que são mais fortes; e difuso dada a categoria social abarcada por esse direito ser tão grande, que alcança toda a sociedade humana.

O mesmo autor adverte sobre a peculiaridade bivalente do direito do consumidor; isso porque, como surgiu num momento de transição pertence tanto a segunda geração de direitos humanos fundamentais (direito social categorial) quanto a terceira (direito difuso transindividual).

Após seis ${ }^{4}$ experiências constitucionais, o Brasil consolida em 05 de outubro de 1988 a atual Constituição da República Federativa, adjetivada por Ulisses Guimarães como cidadã. No que tange a proteção do consumidor, suas principais diretrizes estão no: artigo $5^{\circ}$, inciso XXXII, que estabelece como direito e garantia fundamental a promoção da defesa do consumidor pelo Estado, na forma da lei; artigo 170, inciso V, a defesa do consumidor como princípio geral da ordem econômica; e artigo 24, inciso VIII, a competência concorrente entre a União, Estados e Distrito Federal para legislar sobre consumidor.

O artigo 48 dos Atos das Disposições Constitucionais Transitórias determinou ao Congresso Nacional a elaboração do Código de Proteção ao Consumidor, no prazo de 120 (cento e vinte) dias contados da promulgação da Constituição. Todavia, apenas em 11 de setembro de 1990 o ex-Presidente da República Fernando Collor sancionou a Lei n ${ }^{\circ}$ 8.078, composta por 119 (cento e dezenove) artigos, devidamente publicada no Diário Oficial da União, com vacatio legis de 180 (cento e oitenta) dias, apelidada de Código de Defesa do Consumidor (CDC).

Cotidianamente as pessoas celebram contratos (escritos ou verbais) para benefício próprio ou de terceiros, seja para o desenvolvimento da atividade econômica empresarial ou não, ou para estipular obrigações outras. O contrato é válido e eficaz quando os contratantes exteriorizam a manifestação de vontade de forma livre e consciente para solenizarem uma contraprestação que deverá ser adimplida no futuro próximo ou remoto.

No ambiente contratual há relações eminentemente civis, guiadas pela legislação civil (Código Civil de 2002) e relações consumeristas, regidas pelo CDC; serão estas últimas o objeto deste trabalho.

Nos contratos de consumo nem sempre a execução do acordo firmado é fidedigna com as cláusulas estipuladas (seja explícitas ou implícitas), conturbando a relação e causando

\footnotetext{
${ }^{4}$ Houveram no Brasil Constituições nos anos de 1824, 1891, 1934, 1937, 1946, 1967 e, finalmente, a de 1988. Alguns doutrinadores consideram a Emenda $n^{\circ} 1$ promulgada pela Junta Militar na vigência da Constituição de 1967, como uma verdadeira Constituição (datada de 1969), mas oficialmente não há esse reconhecimento.
} 
prejuízos diretos para uma das partes. Este cenário de arbitrariedade contratual verifica-se de sobremaneira entre o fornecedor ${ }^{5}$ em detrimento do consumidor ${ }^{6}$.

\subsection{DIREITO DE ARREPENDIMENTO}

É desejável ao fornecedor a venda rápida e numerosa de seus produtos ou serviços ao maior leque possível de futuros consumidores e, para tanto, ele investe em inúmeras abordagens para convencer a aquisição deles, seja no estabelecimento comercial ou fora dele.

Ao oferecer o produto ou serviço no domicílio da pessoa - prática conhecida como "vendas de porta em porta" -, por catálogos, telefone ou usando técnicas de marketing agressivo, o fornecedor tendenciosamente compeli o cliente a adquiri-los no ato, sem uma prévia reflexão de conveniência ou análise física e real dos mesmos.

O contato direto com o bem ou o serviço contratado será apenas em momento posterior e, caso não sejam atendidas as expectativas do cliente, a reclamação restará prejudicada tanto pelas dificuldades de localização do vendedor (a pessoa que diretamente o abordou), quanto do fornecedor (por exemplo, o estabelecimento comercial é em outra cidade ou município), deixando-o em uma situação desvantajosa.

Neste contexto, exsurge o direito de arrependimento a fim de reequilibrar a relação consumerista, concedendo ao consumidor o direito de desistir do contrato celebrado no prazo de 7 (sete) dias a contar da assinatura ou da tradição, conforme o artigo 49 do CDC, in verbis:

Art. 49. O consumidor pode desistir do contrato, no prazo de 7 dias a contar de sua assinatura ou do ato de recebimento do produto ou serviço, sempre que a contratação de fornecimento de produtos e serviços ocorrer fora do estabelecimento comercial, especialmente por telefone ou a domicílio. (BRASIL, 1990a)

Logo são requisitos cumulativos para exercício desta benesse que (a) a celebração do contrato tenha sido fora do estabelecimento comercial e (b) a rescisão contratual pleiteada dentro do prazo decadencial.

\footnotetext{
${ }^{5}$ Como o CDC considera em seu artigo $3^{\circ}$ que "fornecedor é toda pessoa física ou jurídica, pública ou privada, nacional ou estrangeira, bem como os entes despersonalizados, que desenvolvem atividade de produção, montagem, criação, construção, transformação, importação, exportação, distribuição ou comercialização de produtos ou prestação de serviços" (BRASIL, 1990a), será utilizado neste texto a expressão fornecedor para abranger tanto o fornecedor, como o produtor e o comerciante.

${ }^{6}$ Dispõe o CDC: “Art. $2^{\circ}$. Consumidor é toda pessoa física ou jurídica que adquire ou utiliza produto ou serviço como destinatário final. Parágrafo único. Equipara-se a consumidor a coletividade de pessoas, ainda que indetermináveis, que haja intervindo nas relações de consumo. ” (BRASIL, 1990a)
} 
Importante ressaltar que o consumidor não precisa justificar seu arrependimento, de modo que qualquer obrigatoriedade, ainda que contratual, é totalmente ilegítima e ilegal, nos termos do artigo $51, \S 1^{\circ}$, incisos II e III do CDC.

$\mathrm{O}$ arrependimento poderá ser feito da mesma forma em que foi firmado o contrato, sendo aconselhável ao consumidor guardar os números de protocolo de atendimento para atestar a contratação e a desistência do objeto convencionado. Por exemplo, o consumidor que contratou um serviço por telefone poderá dentro do prazo legal informar pelo mesmo meio ao contratante o seu arrependimento.

O adimplemento monetário parcial ou integral do consumidor pelo produto ou serviço contratado e seus respectivos acessórios deverá ser atualizado e imediatamente devolvido pelo fornecedor (artigo 49, parágrafo único do CDC).

No que tange aos encargos com o envio do produto (por exemplo, serviço postal) ou desfazimento do serviço, eles serão de responsabilidade do fornecedor, conforme o Informativo $\mathrm{n}^{\mathrm{o}}$ 0528/2013 da Segunda Turma do Superior Tribunal de Justiça no julgamento do REsp 1.340.604-RJ de relatoria do Ministro Mauro Campbell Marques.

\footnotetext{
Aceitar o contrário significaria criar limitação ao direito de arrependimento legalmente não prevista, de modo a desestimular o comércio fora do estabelecimento, tão comum nos dias atuais. Deve-se considerar, ademais, o fato de que eventuais prejuízos enfrentados pelo fornecedor nesse tipo de contratação são inerentes à modalidade de venda agressiva fora do estabelecimento comercial (pela internet, por telefone ou a domicílio). (INFORMATIVO Nº528 DO STJ, 2013)
}

Mesmo que o consumidor já tenha pago as despesas para o restabelecimento da situação anterior, os valores deverão ser prontamente restituídos pelo fornecedor com a devida correção monetária, como meio de impedir a mitigação do exercício do direito e eventual enriquecimento ilícito.

As cláusulas contratuais que guardam correspondência com as hipóteses dos incisos I ao XVI do artigo 51 do CDC são consideradas abusivas e, portanto, nulas de pleno direito. Assim caso uma cláusula restrinja o direito de arrependimento obrigando o consumidor a motivar a desistência para rescindir o contrato, ela deverá ser considerada e declarada nula.

Outrossim, as cláusulas de inadimplemento contratual também não poderão ser reclamadas pelo fornecedor contra o consumidor que exerceu o seu direito de arrependimento, consoante as diretrizes legais e o princípio da boa-fé. 
Frisa-se o direito de arrependimento não coaduna ou prospera com a violação de princípios consumeristas, máxime o da boa-fé nos negócios jurídicos, de modo que a sua observância incumbe tanto ao fornecedor quanto ao consumidor.

Para a validade do arrependimento o produto deve ser entregue sem quaisquer violações que denotem o seu uso, com todos os acessórios que o acompanharam. No caso da prestação de serviço, os produtos e instrumentos utilizados na instalação também devem ser devolvidos com o desfazimento, salvo caso fortuito ou força maior em ambas as situações.

Com a evolução das tecnologias da informação e comunicação, a forma como as pessoas se relacionam e contratam também mudou, principalmente com a difusão da internet e dos aparelhos eletrônicos, surgindo um novo nicho negocial que será explorado no próximo capítulo.

\section{A RELAÇÃO COMERCIAL NA SOCIEDADE DA INFORMAÇÃO}

A Revolução Industrial causou impactos significativos nos meios de produção, no comércio, nas relações humanas e na seara jurídica. Na contemporaneidade, com a evolução dos meios de comunicação, o surgimento do computador e as transformações decorrentes das novas tecnologias há um novo marco histórico.

A partir do século XX inicia a Revolução Informacional com "a finalidade de desenvolver as tecnologias de produção, por meio do acúmulo do conhecimento e da facilitação de seu acesso a todas as pessoas." (LISBOA, 2009, p.6) Roberto Sinise Lisboa elenca como principais efeitos desta Revolução:

1.) A transnacionalização e o surgimento de blocos econômicos. Há um movimento socioeconômico de integração mundial e contrário ao estabelecimento de um Estado superior, o que leva aos inevitáveis conflitos de interesses entre Estados e macroempresas e seus lugares de atuação.

2.) $\mathrm{O}$ e-commerce, proporcionando-se a aquisição de produtos e serviços através da rede, o que ocasiona inúmeras questões sobre: - o problema da atribuição da autoria de documentos eletrônicos e da assinatura digital; - o problema da validade do documento eletrônico original e copiado; - a proteção dos direitos intelectuais, a título de propriedade industrial ou de direito autoral; - a proteção dos direitos de propriedade na web; - a oferta e a publicidade eletrônica; - os contratos eletrônicos; - a proteção do consumidor.

3.) A economicidade da informação, que possui um valor econômico reconhecido, integrando-se como ativo intelectual da pessoa e, portanto, vindo a fazer parte do patrimônio pessoal.

4.) A formação de banco de dados, extremamente útil para a análise e situações relativas a negociações preliminares, estratégias de negociação, contratos preparatórios e repercussão de eventual responsabilidade pré-contratual. 
5.) A transferência eletrônica de dados, proporcionando-se o acesso à informação e o estabelecimento de novas limitações.

6.) O estabelecimento de normas comunitárias, com vistas a uma uniformização do tratamento legislativo sobre a matéria. (2009, p. 6-7)

$\mathrm{O}$ aperfeiçoamento da internet e sua difusão global aliada a generalização do computador intensificaram a revolução informacional e rapidamente as relações humanas tornaram-se virtualizadas, ao ponto da atual sociedade ser adjetivada como "Sociedade da Informação ${ }^{7 \%}$.

\begin{abstract}
A sociedade da informação não é um modismo. Representa uma profunda mudança na organização da sociedade e da economia, havendo quem a considere um novo paradigma técnico-econômico. É um fenômeno global, com elevado potencial transformador das atividades sociais e econômicas, uma vez que a estrutura e a dinâmica dessas atividades inevitavelmente serão, em alguma medida, afetadas pela infraestrutura de informações disponível. É também acentuada sua dimensão políticoeconômica, decorrente da contribuição da infraestrutura de informações para que as regiões sejam mais ou menos atraentes em relação aos negócios e empreendimentos. Sua importância assemelha-se à de uma boa estrada de rodagem para o sucesso econômico das localidades. Tem ainda marcante dimensão social, em virtude do seu elevado potencial de promover a integração, ao reduzir as distâncias entre pessoas e aumentar o seu nível de informação. (SOCIEDADE DA INFORMAÇÃO NO BRASIL, 2000, p.5) (grifo nosso)
\end{abstract}

As mutações sociais pela Era da informação mais que sensitivas são tangíveis, alcançando diretamente a economia (como a economia do conhecimento $^{8}$ ), as relações comerciais e a atividade empresarial que prescindem de atualização (mister tecnológica) para continuarem a existir. "Afinal, na sociedade da informação, os ativos do conhecimento determinam o sucesso ou o fracasso da organização e prevalecem sobre os ativos físicos e financeiros." (LISBOA, 2009, p. 14) Outrossim,

O capital intelectual se constitui em um dos tópicos mais importantes do mundo negocial da atualidade, ao lado da gestão do conhecimento. Percebeu-se, afinal, que os ativos tangíveis das organizações - dinheiro, terrenos e prédios, instalações, equipamentos e outros itens do balanço patrimonial - são muito menos valiosos que os ativos intangíveis - patentes, direitos autorais, bens da era da informação (como bancos de dados e softwares), e, ainda, capacidades, culturas, habilidades, etc. (LISBOA, 2009, p. 16)

\footnotetext{
${ }^{7}$ A expressão foi utilizada pela primeira vez em 1993 por Jacques Delors, presidente da Comissão Europeia, durante o Conselho Europeu de Kopenhagen. Embora alguns doutrinadores não concordam com a sua conceituação, filia-se ao entendimento de Lisboa de que ela é suficiente para a atual contextualização social.

${ }^{8}$ Os três pilares da economia do conhecimento são: "a) o conhecimento impregna tudo o que compramos, vendemos e produzimos; b) os ativos do conhecimento, isto é, o capital intelectual, passou a ser mais importantes para as empresas que os ativos financeiros e físicos; c) prosperar na nova economia e explorar esses novos ativos significa a maior utilização de novas técnicas de gestão, novas tecnologias e novas estratégias. " (LISBOA, 2009, p. 9)
} 
Para acompanharem o progresso comercial os meios de produção da atividade empresarial clássica rapidamente precisaram ser modernizados e incorporados ao complexo mundo digital, exsurgindo o estabelecimento empresarial virtual.

Estabelecimento empresarial virtual é o complexo de bens organizados pelo empresário, dotado de nome de domínio, título e ponto eletrônico, destinado e suficientemente capaz para o exercício da empresa, na rede mundial de computadores, operado e explorado por Empresário ou sociedade empresária. (MICHEL, 2014, p.12)

Transações bancárias, contratações, diminuição dos custos administrativos, entrega de produtos por downloads, tudo exclusivamente realizado pela rede mundial de comunicação são exemplos das ações vanguardistas comerciais do consolidado mercado eletrônico, também denominado comércio eletrônico ou e-commerce.

O comércio eletrônico subverteu a lógica de funcionamento dos mercados tradicionais, impondo-lhe novas características: fácil acesso à informação; diminuição dos custos de transação; substituição dos intermediários tradicionais por novos tipos de agentes que atuam na ponta da cadeia produtiva, junto ao consumidor final, fazendo eles mesmos toda a conexão com os produtores de bens e serviços; eliminação das distâncias físicas e funcionamento ininterrupto em todas as regiões do mundo. (SOCIEDADE DA INFORMAÇÃO NO BRASIL, 2000, p.18)

$\mathrm{O}$ e-commerce rompeu as fronteiras geográficas permitindo que pessoas e empresas localizadas em pontos antagônicos do globo terrestre realizassem contratações instantaneamente, utilizando recursos eletrônicos (computador, tablete, smartphone...) conectados a um servidor de internet, com as mesmas responsabilidades de uma negociação pessoal.

Desde do ano 2000 a E-bit/Buscapé Company realiza um relatório denominado Webshoppers sobre o comércio eletrônico no Brasil. Conforme a $33^{\mathrm{a}}$ edição do relatório, o Brasil obteve em 2015 um faturamento de R \$ 41,3 bilhões de reais no comércio eletrônico, um crescimento nominal de 15,3\% comparado ao ano de 2014 ( $\mathrm{R} \$ 35,8$ bilhões de reais).

Conquanto em 2015 o número de pedidos no e-commerce brasileiro tenha alcançado um volume de crescimento de apenas 3\%, em comparação a 2014 que foi de 17\%, foram feitos 
106,2 milhões de pedidos. Registra-se que esse foi o maior número de pedidos nos últimos cinco anos ${ }^{9}$.

A expressão e-business abrange diversos tipos de negócios realizados em ambiente virtual (comerciais, administrativas e contábeis), como os contratos eletrônicos. Para comprovar a veracidade das negociações virtuais é importante a formalização da exteriorização da vontade das partes, por isso o contrato eletrônico tem uma posição de destaque neste ambiente.

Enquanto o contrato tradicional é corporificado em folhas de papel e assinado a punho pelos contratantes, o contrato eletrônico é exclusivamente digital e firmado por assinatura digital. Destarte, a forma como o contrato é realizado é que definirá se ele é eletrônico ou não.

Todos os requisitos de validade e eficácia, a legislação e os princípios contratuais que instruem a contratação tradicional também devem ser igualmente observados pelos contratantes virtuais.

Dentre os tipos de transações e-business ${ }^{10}$ acentua-se a B2C (business to consumer) relativa aos "negócios jurídicos de escopo diverso que efetivamente envolvem um consumidor como destinatário final do produto ou dos serviços. Estes sites são voltados para a venda ou prestação de serviços no varejo". (SIMÃO FILHO, 2012, p.4)

Especificamente neste tipo de negociação, cada vez maior no Brasil, denota-se uma vulnerabilidade do consumidor virtual em relação ao fornecedor também virtual, exigindo-se uma atualização da tutela protetiva estatal. O apogeu brasileiro foi com o Marco Civil da Internet.

\subsection{O MARCO CIVIL DA INTERNET E OS CONTRATOS ELETRÔNICOS}

A ampliação da internet e das controvérsias deste serviço no Brasil implicaram na necessidade de atualização da legislação pátria, refletindo na seara consumerista com a edição

\footnotetext{
${ }^{9}$ A $33^{\text {a }}$ edição do Webshoppers (2016, p. 29) aponta que em 2011 o número de pedidos no e-commerce brasileiro foi 53,7 milhões (crescimento de 34\%), em 2012 66,7 milhões (25\%), em 2013 88,3 milhões (32\%), 2014 103,4 milhões (17\%) e em 2015 106,5 milhões (3\%).

${ }^{10}$ As relações comerciais em ambiente eletrônico podem ser dos seguintes tipos: (a) B2B (business-to-business): transações entre empresas; (b) B2C/C2B (business-to-consume / consumer-to-business): transações entre empresas e consumidores; (c) B2G/G2B (business-to-government / governmentto-business): transações envolvendo empresas e governo; (d) C2C (consumer-to-consumer): transações entre consumidores finais; (e) $\mathrm{G} 2 \mathrm{C} / \mathrm{C} 2 \mathrm{G}$ (government-to-consumer / consumer-togovernment): transações envolvendo governo e consumidores finais e (f) G2G (government-to-government): transações entre governo e governo. (SOCIEDADE DA INFORMAÇÃO NO BRASIL, 2000, p. 18)
} 
da Lei n ${ }^{\circ} 12.965$ de 23 de abril de 2014, conhecida como Marco Civil da Internet, que estabelece princípios, garantias, direitos e deveres para o uso da internet.

A Lei $\mathrm{n}^{\circ} 12.965$ no artigo $5^{\circ}$, inciso I conceitua internet como "o sistema constituído do conjunto de protocolos lógicos, estruturado em escala mundial para uso público e irrestrito, com a finalidade de possibilitar a comunicação de dados entre terminais por meio de diferentes redes. " (BRASIL, 2014f)

Diante de inúmeras violações aos direitos personalíssimos ${ }^{11}$, o Marco Civil da Internet garante como direito dos usuários a inviolabilidade da intimidade e da vida privada, sigilo de suas comunicações virtuais, não fornecimento à terceiros de dados pessoais sem autorização expressa e exclusão definitiva dos dados pessoais (artigo $7^{\circ}$, incisos I, II, III, VII, IX e X). Reforça ainda no artigo $8^{\circ}$ que o direito à privacidade é condição para o pleno exercício do direito de acesso à internet, sendo nula cláusula contrária a este dispositivo.

O uso da internet tornou-se essencial para o exercício da cidadania. Logo, os valores sociais, éticos e morais devem ser respeitados no ambiente virtual, máxime nas relações comerciais em que há a contratação instantânea com fornecedores nacionais e internacionais com a veiculação de dados pessoais que requerem sigilo.

Destarte, aplica-se ao e-commerce os princípios da proteção da privacidade e dos dados pessoais, e da liberdade dos modelos de negócios promovidos na internet (artigo $3^{\circ}$, incisos II, III e VIII da Lei $\mathrm{n}^{\circ}$ 12.965/2014), sem prejuízo de outros princípios estabelecidos pela Lei.

A Lei $n^{\circ} 12.965 / 2014$ restringe seu conteúdo mais aos contratos de provisão de conexão de internet, isso porque, antes de sua promulgação já estava em vigor o Decreto $n^{\circ}$ 7.962 de 15 de março de 2013 que regulamenta especificadamente a contratação no comércio eletrônico.

$A b$ initio, o Decreto (artigo $1^{\circ}$ ) elenca os três objetivos básicos que pretende regulamentar, são eles: (a) a necessidade de informações claras a respeito do produto, serviço e fornecedor, (b) atendimento facilitado ao consumidor e (c) respeito ao direito de arrependimento.

\footnotetext{
${ }^{11}$ A título de exemplo, cita-se os casos emblemáticos e de repercussão nacional e judicial da apresentadora Xuxa Meneghel que não queria seu nome atrelado a expressão pedofilia, quando pesquisado no site Google; a filmagem clandestina e posterior divulgação não autorizada pelos interessados no site You Tube do encontro íntimo da atriz Daniella Cicarelli com seu namorado em uma praia na Espanha; e da atriz Carolina Dieckmann que teve suas fotos íntimas divulgadas na internet, após seu computador ser invadido por um terceiro não autorizado.
} 
O estabelecimento comercial puro tornou-se impraticável, haja vista a obrigatoriedade de constar em local de destaque e de fácil visualização no sítio eletrônico o endereço físico do empreendimento e outros dados identificadores (nome empresarial, número de inscrição do fornecedor e CNPJ - Cadastro Nacional de Pessoa Jurídica).

Ademais, o fornecedor deve apresentar informações claras e ostensivas quanto à fruição da oferta, modalidades de pagamento, disponibilização, forma e prazo de entrega do produto, discriminação completa do preço e as características essenciais do produto ou serviço (artigo $2^{\circ}$ do Decreto $\mathrm{n}^{\mathrm{o}} 7.962$ ).

Para as ofertas de compra coletiva ou modalidades análogas o fornecedor direto também deverá informar a quantidade mínima de consumidores para a efetivação do contrato, o prazo para utilização da oferta pelo consumidor e identificar tanto o fornecedor (primário ou secundário) do sítio eletrônico quanto o do produto ou serviço ofertado (artigo $3^{\circ}$ do Decreto ${ }^{\circ}$ 7.962).

O fornecedor no e-commerce deve viabilizar o atendimento imediato, facilitado e eficaz do consumidor, apresentar o contrato antes da celebração do acordo, assim como, mecanismos para identificação e correção célere de erros durante a contratação. Ademais deve disponibilizar amplamente o contrato, manter SAC - Serviço de Atendimento ao Consumidor, confirmar o recebimento de demandas e utilizar mecanismos de segurança para pagamento e tratamento de dados dos consumidores (artigo $4^{\circ}$ do Decreto $n^{\circ} 7.962$ ).

Os meios para o exercício do direito de arrependimento do consumidor devem ser informados de forma clara e ostensiva, podendo ser realizado pela mesma ferramenta utilizada para a contratação, com a rescisão dos contratos acessórios sem ônus ao consumidor (artigo $5^{\circ}$, $\S \S 1^{\circ}, 2^{\circ}$ e $3^{\circ}$ do Decreto $\left.n^{\circ} 7.964\right)$.

Aliás, o fornecedor deverá comunicar imediatamente ao consumidor do recebimento do pleito de arrependimento, bem como à instituição financeira ou à administradora do cartão de crédito ou similar para que a "transação não seja lançada na fatura do consumidor" ou "seja efetivado o estorno do valor, caso o lançamento na fatura já tenha sido realizado" (BRASIL, 2013b), conforme o artigo $5^{\circ}, \S^{\circ}$, incisos I e II e $\S 4^{\circ}$ do Decreto em tela.

Frisa-se que a oferta vincula o proponente, logo, "as contratações no comércio eletrônico deverão observar o cumprimento das condições da oferta, com a entrega dos produtos e serviços contratados, observados prazos, quantidade, qualidade e adequação" (BRASIL, 2013e), (artigo $6^{\circ}$ do Decreto $\left.n^{\circ} 7.962\right)$. 
O desrespeito total ou parcial das disposições estabelecidas no Decreto $\mathrm{n}^{\circ} 7.962$ implicarão além das sanções civis e penais, nas sanções administrativas previstas no artigo 56 do $\mathrm{CDC}^{12}$, nos termos do artigo $7^{\circ}$ do próprio Decreto.

Ante o exposto, denota-se a carência de diretrizes pragmáticas e claras ao consumidor para utilização desse direito tão expressivo nas contratações eletrônicas, sendo imprescindível a atualização legal do exercício do direto de arrependimento virtual.

\section{AS NOVAS DIRETRIZES LEGAIS PARA O DIREITO DE ARREPENDIMENTO VIRTUAL}

A crescente virtualização das relações comerciais consolidou um novo ambiente negocial denominado e-commerce, permitindo transações não-presenciais (e-business) globais e momentâneas, que são primordiais para a sociedade informacional pretensa à celeridade, consumo e tecnologia.

Dada a alta conectividade das pessoas no ambiente virtual, independentemente da idade, as empresas virtuais encontraram no ciberespaço um local eficiente e rápido para o marketing agressivo global. Com propagandas e ofertas incessantes nos websites e e-mails, os consumidores ficaram ainda mais vulneráveis para realizarem compras prejudiciais e superendividamentos.

Incontestável a modernidade normativa da proteção e defesa do direito do consumidor no Brasil positivado pelo CDC promulgado em 1990. No entanto, com as mutações mercadológicas realizadas pela Revolução Informacional, imperiosa a modernização dos direitos consumeristas relacionados aos contratos virtuais, máxime em relação ao direito de arrependimento.

O Projeto de Lei do Senado (PLS) no 281/2012 de autoria do Senador José Sarney, aprovada pelo Senado Federal em 2015 e remetido em novembro do mesmo ano à Câmara dos Deputados, tenciona alterar o CDC para aperfeiçoar o Capítulo I do Título I e o artigo $9^{\circ}$ da Lei de Introdução às Normas de Direito Brasileiro no que tange aos contratos internacionais

\footnotetext{
${ }^{12} \mathrm{O}$ artigo 56 do $\mathrm{CDC}$ elenca como sanções administrativas a serem aplicadas pela autoridade administrativa competente: multa, apreensão do produto, inutilização do produto, cassação do registro do produto junto ao órgão competente, proibição de fabricação do produto, suspensão de fornecimento de produtos ou serviço, suspensão temporária de atividade, revogação de concessão ou permissão de uso, cassação de licença do estabelecimento ou de atividade, interdição, total ou parcial, de estabelecimento, de obra ou de atividade, intervenção administrativa e imposição de contrapropaganda.
} 
comerciais e de consumo e obrigações extracontratuais e, por fim, dispor sobre o comércio eletrônico.

Na casa revisora o PLS n 281/2012 está sob regime de tramitação prioritária, com a numeração Projeto de Lei (PL) nº 3514/2015, sendo apensado ao PL nº 4906/2001 (dispõe sobre comércio eletrônico). Sua última movimentação foi em 20/04/2016 pela Mesa Diretora para que o PL n ${ }^{\circ} 4678 / 2016$ fosse apensado a ele.

O PLS no 281/2012 inclui no Capítulo IV - Da qualidade de produtos e serviços, da prevenção e da reparação de danos do CDC a seção VII - Do comércio eletrônico para aperfeiçoar as diretrizes consumeristas do comércio eletrônico e à distância, estabelecendo no artigo 45-A:

\footnotetext{
Art. 45-A. Esta seção dispõe sobre normas gerais de proteção do consumidor no comércio eletrônico e a distância, visando a fortalecer sua confiança e assegurar sua tutela efetiva, mediante a diminuição da assimetria de informações, a preservação da segurança nas transações e a proteção da autodeterminação e da privacidade dos dados pessoais. (BRASIL, 2012c) (grifo nosso)
}

Dentre as alterações colacionadas pelo projeto de lei em tela, o presente artigo restringirá àquelas relacionadas ao direito de arrependimento do consumidor na contratação à distância. Essa contratação está conceituada no artigo 49, § $2^{\circ}$ do PLS no 281 como "aquela efetivada fora do estabelecimento ou sem a presença física simultânea do consumidor e do fornecedor, especialmente em domicílio, por telefone, por reembolso postal ou por meio eletrônico ou similar." (BRASIL, 2012c).

Ressalta-se a possibilidade de contratação à distância equiparada, que ocorre quando não é oportunizado ao consumidor o contato direto ou o conhecimento do produto ou serviço, mesmo estando no estabelecimento físico, em razão de não o ter em exposição ou pela impossibilidade ou dificuldade de acesso ao conteúdo (artigo 49, $\S 3^{\circ}$ do PLS n 281/2012).

\footnotetext{
Esse alargamento no direito ao arrependimento incluindo as compras em estabelecimento comercial é de extrema importância. Isso porque, o art. 49 do CDC, atualmente, é omisso nos casos em que o consumidor, por exemplo, adentra uma loja de móveis e escolhe o produto por catálogo pelo fato do fornecedor não possuir um produto idêntico em exposição. A ampliação do direito ao arrependimento é notória, pois sua atual aplicação ocorre por analogia, fato este que leva à insegurança jurídica no âmbito processual. (CABRAL; MOZELI. [201-?])
}

O termo inicial para a contagem do prazo decadencial de 7 (dias) para o consumidor manifestar seu direito de arrependimento é estendido, iniciando a partir da aceitação da oferta, 
do recebimento ou da disponibilidade do produto ou serviço, com a ressalva de que será considerado o evento que ocorrer por último (artigo 49, caput do PLS nº 281/2012).

O consumidor arrependido deverá devolver o produto com todos os seus acessórios e nota fiscal, e nas operações de crédito (retirada de recursos ou transação de financiamento) o valor total do crédito contratado já entregue, acrescido dos juros incidentes até a data da efetiva devolução. Os contratos acessórios serão rescindidos automaticamente, sendo permitida a cobrança de tarifas e tributos apenas quando aplicável (artigo $49, \S \S 4^{\circ}$ e $5^{\circ}$ do PLS $n^{\circ}$ 281/2012).

Nos termos do artigo 49, $\S 9^{\circ}$ do PLS $n^{\circ}$ 281/2012, ao receber o pedido de arrependimento do consumidor o fornecedor é obrigado a enviar imediatamente e de forma individualizada a confirmação do recebimento da manifestação de arrependimento.

\footnotetext{
O PLS buscou absorver um dos mandamentos nucleares do direito do consumidor, que é o dever de informar, corroborado pelo princípio da boa-fé objetiva. A necessidade dessa disposição nasce para coibir possíveis práticas de omissão dos fornecedores quanto ao direito de arrependimento. Os fornecedores deverão por obrigação informar de forma clara e ostensiva, os meios adequados, facilitados e eficazes disponíveis para o exercício do direito de arrependimento do consumidor. (CABRAL; MOZELI. [201-?])
}

Neste diapasão, demonstrado objetivamente o arrependimento do consumidor, o fornecedor a pedido ou não do consumidor deverá comunicar imediatamente a instituição financeira ou a administradora do cartão de crédito ou similar para que:

Artigo 49, $\S 6^{\circ}$ do PLS n ${ }^{\circ} 281:$ (...) I - a transação não seja lançada na fatura do consumidor; II - seja efetivado o estorno do valor, caso a fatura já tenha sido emitida no momento da comunicação e III - caso o preço já tenha sido total ou parcialmente pago, seja lançado o crédito do respectivo valor na fatura a ser emitida posteriormente à comunicação. (BRASIL, 2012c)

O descumprimento do fornecedor em devolver os valores adimplidos a qualquer título pelo consumidor arrependido, violando as disposições do parágrafo $1^{\circ}$ do artigo 49 do atual CDC e do $\S 6$ do artigo 49 do PLS nº 281/2012, implicará na devolução da quantia em dobro (artigo 49, $\S 7^{\circ}$ do PLS n ${ }^{\circ} 281 / 2012$ ).

Os meios para o exercício do direito de arrependimento deverão ser facilitados e eficazes, contemplando, no mínimo, o mesmo modo utilizado para a contratação, devendo o fornecedor informá-los previamente ao consumidor de forma clara e ostensiva (artigo $49, \S 8^{\circ}$ do PLS n ${ }^{\circ} 281 / 2012$ ). 
O projeto de lei avança ao estipular uma proteção particularizada aos consumidores de transporte aéreo ${ }^{13}$, que gozarão de um prazo maior para o exercício do direito de arrependimento a ser estipulado pelas agências reguladoras, como a ANAC - Agência Nacional de Aviação Civil.

O CDC e o PLS nº 281/2012 não estipulam um prazo máximo para a devolução dos valores já pagos pelo consumidor arrependido ao fornecedor, favorecendo uma brecha interpretativa da aplicação real do conceito da expressão “imediatamente". À visto disso, tramita na Câmara dos Deputados o Projeto de Lei n 4678/2016 de autoria do Deputado Márcio Marinho para tipificar o descumprimento do artigo 49 do CDC, acrescentado a este diploma legal o artigo 74-A.

Art. 74-A. Deixar de devolver de imediato e monetariamente atualizados quaisquer valores pagos pelo consumidor durante o período compreendido entre a compra e o exercício do direito de arrependimento pelo consumidor.

Pena - Detenção de um a seis meses ou multa. (BRASIL, 2016e)

O referido deputado justifica seu projeto aduzindo que embora haja a penalidade genérica no CDC e o pedido judicial de indenização, a situação ainda é excessivamente penosa ao consumidor arrependido.

A título de informação, detectamos [o Deputado Márcio Marinho e seus assessores] que só no ano de 2015 houveram mais de 47.000 (quarenta e sete mil) demandas nos Procons, relativas ao descumprimento do art. 49 do CDC. Logo, percebe-se que a causa preocupa, pois não são poucos casos isolados que ocorrem, mas sim um número considerável de infringência à Lei. (BRASIL, 2016e)

Por fim, o PLS n ${ }^{\circ}$ 283/2012 ${ }^{14}$ de autoria do senador José Sarney aprovado pelo Senado Federal e encaminhado à Câmara dos Deputados para revisão, atualmente denominado PL n ${ }^{\circ}$ 3515/2015 traz uma importante previsão acerca do superendividamento dos consumidores.

O superendividamento será considerado para fins legais como "a impossibilidade manifesta de o consumidor, pessoa natural, de boa-fé, pagar a totalidade de suas dívidas de

\footnotetext{
${ }^{13}$ Dispõe o artigo 49-A do PLS n ${ }^{\circ}$ 281/2012: "Sem prejuízo do direito de rescisão do contrato de transporte aéreo antes de iniciada a viagem, nos termos do art. 740, $\S 3^{\circ}$, da Lei no 10.406 , de 10 de janeiro de 2002 (Código Civil), o exercício do direito de arrependimento do consumidor de passagens aéreas poderá ter seu prazo diferenciado, em virtude das peculiaridades do contrato, por norma fundamentada das agências reguladoras. Parágrafo único. A regulamentação prevista no caput deverá ser realizada no prazo máximo de 180 (cento e oitenta) dias após a entrada em vigor desta Lei". (BRASIL, 2012c)

${ }^{14} \mathrm{O}_{\text {PLS n }}{ }^{\circ}$ 283/2012 visa alterar a Lei no ${ }^{8.078}$, de 11 de setembro de 1990 (Código de Defesa do Consumidor), e o artigo 96 da Lei ${ }^{\circ} 10.741$, de $1^{\circ}$ de outubro de 2003 (Estatuto do Idoso), para aperfeiçoar a disciplina do crédito ao consumidor e dispor sobre a prevenção e o tratamento do superendividamento.
} 
consumo, exigíveis e vincendas, sem comprometer seu mínimo existencial, nos termos da regulamentação" (BRASIL, 2012c), (artigo 54-A, §1 do PLS nº 283).

A Era digital possibilitou a contratação imediata e uma intensa propagação de produtos e serviços de forma ininterrupta, fortalecendo o consumismo imoderado pelas diversas faixas etárias, principalmente das crianças que são facilmente manipuladas pelo marketing hostil, prejudicando a saúde financeira familiar. Por isso será classificada pelo PLS n 283 como publicidade abusiva àquela:

Artigo 37. $\S 2^{\circ}$. I - discriminatória de qualquer natureza, a que incite à violência, explore o medo ou a superstição, se aproveite da deficiência de julgamento e experiência da criança ou desrespeite valores ambientais, bem como a que seja capaz de induzir o consumidor a se comportar de forma prejudicial ou perigosa à sua saúde ou segurança;

II - que contenha apelo imperativo de consumo à criança, que seja capaz de promover qualquer forma de discriminação ou sentimento de inferioridade entre o público de crianças e adolescentes ou que empregue criança ou adolescente na condição de porta-voz direto da mensagem de consumo. (BRASIL, 2012d) (grifo nosso)

O projeto irá incluir no CDC o Capítulo VI-A - Da prevenção e do tratamento do superendividamento, para conscientizar os particulares do uso do crédito responsável, da educação financeira do consumidor e a prevenção ao déficit orçamentário pessoal.

Ele também propõe a inclusão do Capítulo V - Da conciliação no superendividamento, de modo que o consumidor será responsabilizado por suas dívidas, sem prejuízo de sua dignidade, e ainda irá promover a interação entre os contratantes.

\footnotetext{
Art. 104-A. A requerimento do consumidor superendividado pessoa natural, o juiz poderá instaurar processo de repactuação de dívidas, visando à realização de audiência conciliatória, presidida por ele ou por conciliador credenciado no juízo, com a presença de todos os credores, em que o consumidor apresentará proposta de plano de pagamento com prazo máximo de 5 (cinco) anos, preservados o mínimo existencial, nos termos da regulamentação, e as garantias e as formas de pagamento originalmente pactuadas. (BRASIL, 2012d)
}

Ao incentivar a resolução de conflitos pelos meios alternativos é valorizado o diálogo entre as partes, a emancipação do cidadão (que não deixará sob exclusiva responsabilidade do Estado a solução da lide), acelera a solução da controvérsia, e diretamente desafoga o Poder Judiciário. 
Dada a intensificação do comércio eletrônico e das "armadilhas publicitárias" para incentivar o consumo desfreado, os projetos de lei analisados são expoentes importantes para a ampliação e instrumentalização do direito de arrependimento virtual.

E como são medidas legislativas de alto teor social precisam urgentemente terem otimizadas suas tramitações para, enfim, serem aprovadas; o que não se verifica, pois, o PLS n ${ }^{\circ}$ 281 é uma proposta que está na Casa faz aproximadamente 5 (cinco) anos, corroborando com a violação dos direitos do consumidor através da inércia.

\section{CONSIDERAÇÕES FINAIS}

A busca pelo lucro absoluto pelo sistema capitalista clássico, sem medir as consequências de suas abordagens ao propenso adquirente, impôs ao Estado Social uma atitude positiva frente a violação dos direitos consumeristas em nome do capitalismo selvagem.

Considerando a latente vulnerabilidade dos consumidores em face do poderio econômico do fornecedor, o Código de Defesa do Consumidor restabelece o equilíbrio entre as partes, intensificando a necessidade da tutela estatal específica para com os direitos dos primeiros.

O direito potestativo de arrependimento, previsto no artigo 49 do CDC, atribui ao consumidor o direito de reflexão diante da aquisição impulsiva de um produto ou serviço contratado fora do estabelecimento comercial, especialmente por telefone ou a domicílio. Ele poderá ser exercido no prazo de 7 (sete) dias contados da assinatura do contrato ou da tradição, sem a necessidade de qualquer justificação.

Esse direito é necessário pois, quando o consumidor adquire à distância um objeto pautado na informação e opinião exclusivamente apresentada pelo fornecedor - totalmente parcial, tencionada à comercialização -, sem qualquer acesso físico, ele se sujeita a uma contratação de alto risco, muitas vezes movida pela paixão.

A Revolução Informacional alterou a sociedade e a forma como as relações comerciais se exteriorizam, máxime com o surgimento do e-commerce. O Mercado Eletrônico permitiu a negociação global, instantânea, sem impedimento geográfico, com diminuição de custos e intercâmbio acelerado.

Com a popularização da internet, computadores e smartphones, as contratações eletrônicas cresceram exponencialmente no Brasil, destacando-se os contratos eletrônicos entre fornecedor e consumidor. 
Os contratos eletrônicos apenas diferem na forma como os contratos tradicionais são realizados, haja vista que no primeiro ele será exclusivamente digital e no segundo há a exteriorização em papeis. Assim também são aplicáveis aos contratos eletrônicos os princípios e leis regentes do contrato tradicional.

O ambiente virtual possibilita a veiculação intensa de produtos e serviços a todos os tipos de futuros consumidores, seja criança ou idoso, seduzindo o público ao gasto desenfreado, sem um pré-juízo de valoração.

O direito de arrependimento prescinde de uma propagação e instrumentalização rápida, eficaz e universal nas contratações realizadas eletronicamente. No entanto, o CDC, promulgado em 1990 não foi capaz de prever tais mutações sociais, econômicas e jurídicas da Era informacional, necessitando de uma atualização legal. Conquanto o Marco Civil da Internet (Lei $\left.{ }^{\circ} 12.965 / 2014\right)$ tenha abrilhantado mudanças significativas em relação à proteção de dados particulares, sigilo de informações e veiculação à terceiros desses dados, em relação ao e-commerce carece de especificidades.

Decerto que o Decreto $n^{\circ} 7.962$ de 15 de março de 2013 dispõe sobre contratações eletrônicas, mas as disposições para o exercício do direito de arrependimento são vagas, deixando várias questões sem uma regulamentação completa.

Destarte, para o restabelecimento do status quo de uma contratação à distância que não atendeu as expectativas do consumidor ou mesmo após uma análise de conveniência constatou que não lhe era vantajoso, os projetos de lei PLS $n^{\circ}$ 281/2012, PLS $n^{\circ}$ 283/2012 e PL $n^{\circ}$ 4678/2016 são importantes medidas para modernizar o exercício do direito de arrependimento virtual.

Embora o arrependimento seja mais detalhado no PLS nº 281/2012, ainda há lacunas que devem ser preenchidas para a real e efetiva regulamentação do exercício desse direito pelo consumidor virtual, como o prazo para a devolução dos valores já adimplidos ao fornecedor.

Objetivando fortificar a coerção para que o fornecedor devolva os valores já pagos a qualquer título pelo consumidor arrependido, o PL n ${ }^{\circ} 4678 / 2016$ radicaliza ao tipificar penalmente a conduta de descumprimento do artigo 49 do CDC. O projeto visa inserir no Código Penal o artigo 74-A, estipulando pena de detenção de 1 (um) a 6 (seis) meses ou multa. No entanto, ele não estipula um prazo para a verificação de descumprimento ou não do tipo.

Dotado de alto teor social o PLS no 283/2012 prevê mecanismos de mitigação do superendividamento do consumidor e uso da conciliação para solucionar eventuais conflitos entre os contratantes da relação consumerista. 
Considerando a expansão do ambiente virtual nas relações comerciais, a vulnerabilidade do consumidor despreparado ao marketing agressivo e a oferta global de produtos e serviços, a tramitação desses dispositivos legais denota a aproximação do Estado com a realidade fática social.

Contudo, a postergação do confronto estatal (votação dos parlamentares e sanção presidencial) para a atualização rápida (ou no prazo razoável) do direito de arrependimento mantém as dubiedades para o exercício deste direito, colaborando para a desinformação e vulnerabilidade do consumidor virtual.

\section{REFERÊNCIAS}

BARROS, Sérgio Resende de. Direito do Consumidor e Gerações de Direito. [201-?]. Disponível em: http://www.srbarros.com.br/pt/direito-do-consumidor-e-geracoes-dedireitos.cont. Acesso em: 09 mai. 2016.

BRASIL. Constituição da República Federativa do Brasil. Brasília: Senado, 1988. Disponível

em: http://www.planalto.gov.br/ccivil_03/constituicao/ConstituicaoCompilado.htm. Acesso em: 10 mai. 2016.

(a). Código de Defesa do Consumidor. Lei $\mathrm{n}^{\circ} 8.078$ de 11 set. 1990. Brasília: Planalto, 1990. Disponível em: http://www.planalto.gov.br/ccivil_03/leis/L8078.htm. Acesso em: 10 mai. 2016.

(b). Decreto no 7.962 de 15 mar. 2013. Brasília: Planalto, 2013. Disponível em: http://www.planalto.gov.br/ccivil_03/_ato2011-2014/2013/decreto/d7962.htm. Acesso em: 10 mai. 2016.

(c). Projeto de Lei N. 281, de 2012 (do Senado Federal) PLS N. 281/2012. Altera a Lei n ${ }^{\circ}$ 8.078, de 11 de setembro de 1990 (Código de Defesa do Consumidor), para aperfeiçoar as disposições gerais do Capítulo I do Título I e dispor sobre o comércio eletrônico, e o art. $9^{\circ}$ do Decreto-Lei n 4.657, de 4 de setembro de 1942 (Lei de Introdução às Normas do Direito Brasileiro), para aperfeiçoar a disciplina dos contratos internacionais comerciais e de consumo e dispor sobre as obrigações extracontratuais. Disponível em: http://www.camara.gov.br/proposicoesWeb/prop_mostrarintegra?codteor=1408274\&filename $=\mathrm{PL}+3514 / 2015$. Acesso em: 12 mai. 2016. 
(d). Projeto de Lei N. 283, de 2012 (do Senado Federal) PLS N. 282/2012. Altera a Lei $\mathrm{n}^{\circ}$ 8.078, de 11 de setembro de 1990 (Código de Defesa do Consumidor), e o art. 96 da Lei $\mathrm{n}^{\circ} 10.741$, de $1^{\circ}$ de outubro de 2003 (Estatuto do Idoso), para aperfeiçoar a disciplina do crédito ao consumidor e dispor sobre a prevenção e o tratamento do superendividamento. Disponível em: http://www.camara.gov.br/proposicoesWeb/prop_mostrarintegra;jsessionid=0E9CE441066B2 C45C43DA59772769FCE.proposicoesWeb1 ?codteor $=1408277 \&$ filename $=P L+3515 / 2015$. Acesso em: 12 mai. 2016.

(e). Projeto de Lei N. 4678, de 2016 (da Câmara dos Deputados) PL N. 4678/20016. Acrescenta artigo à Lei $\mathrm{n}^{\circ}$ 8.078, de 11 de setembro de 1990, que dispõe sobre a proteção do consumidor e dá outras providências para tipificar pena pela não devolução dos valores pagos, no caso de exercício do direito de arrependimento pelo consumidor. Disponível em:

http://www.camara.gov.br/proposicoesWeb/prop_mostrarintegra?codteor=1440972\&filename $=$ PL+4678/2016. Acesso em: 12 mai. 2016.

(f). Lei $n^{\circ} 12.965$ de 23 abr. 2014. Brasília: Planalto, 2014. Disponível em: http://www.planalto.gov.br/ccivil_03/_ato2011-2014/2014/lei/112965.htm. Acesso em: 16 abr. 2016.

CABRAL, Hildeliza Lacerda Tinoco Boechat; MOZELI, Kamilla Abreu Costa. A ampliação do Direito de Arrependimento à Luz do Projeto de Lei $\mathbf{n}^{0} 281$ que visa alterar o CDC. [201-?]. Publicada por LexMagister. Disponível em: http://www.lex.com.br/doutrina_24318813_A_AMPLIACAO_DO_DIREITO_DE_ARREPE NDIMENTO_A_LUZ_DO_PROJETO_DE_LEI_N_281_QUE_VISA_ALTERAR_O_CDC. aspx. Acesso em: 12 maio 2016.

E-BIT/BUSCAPÉ. Webshoppers. 33. ed. 2016. Disponível em: http://img.ebit.com.br/webshoppers/pdf/33_webshoppers.pdf. Acesso em: 11 mai. 2016.

LISBOA, Roberto Senise. Proteção do Consumidor na Sociedade da Informação. Revista do Direito Privado da UEL, Londrina, v. 2, n. 1, p.1-27, jan/abr 2009. Quadrimestral. Disponível

em: http://www.uel.br/revistas/direitoprivado/artigos/Roberto_Senise_Lisboa_Proteção_Consumi dor_Sociedade_Informação.pdf. Acesso em: 11 maio 2016.

MICHEL, Vinicius de Paula. O Estabelecimento empresarial virtual: conceito e tutela jurídica. XXIII Encontro Nacional do CONPEDI, Direito Empresarial. Florianópolis: CONPEDI, $2014 . \quad$ Disponível em: http://www.publicadireito.com.br/artigos/?cod=ccea163536ff22f5. Acesso em: 12 mai. 2016.

ORGANIZAÇÃO DAS NAÇÕES UNIDAS (ONU). Resolução no 39/248: Proteção do Consumidor. 1985.

Disponível

em: http://www.egov.ufsc.br/portal/conteudo/resolu\%C3\%A7\%C3\%A3o-daorganiza\%C3\%A7\%C3\%A3o-das-na\%C3\%A7\%C3\%B5es-unidas-onu-n\%C2\%BA-39248de-16-de-abril-de-1985-em-ingl\%C3\%AAs . Acesso em: 09 mai. 2016. 
PAGANOTTI, Ivan. Pressão virtual e regulamentação digital brasileira: Análise comparativa entre o Marco Civil da Internet e a Lei Azeredo. Epitc: Revista Eletrônica Internacional de Economia Política da Informação, da Comunicação e da Cultura, Sergipe, v. 16, n. 2, p.124-142, mai/ago. 2014. Quadrimestral. Disponível em: http://www.seer.ufs.br/index.php/eptic/article/view/2171. Acesso em: 23 ago. 2016.

SIMÃO FILHO, Adalberto. Proteção dos consumidores nos contratos celebrados via internet. Revista Jurisbarretos, Barretos, v. 1, n. 1, p.1-28, 2012. Semestral. Disponível em: http://revistadigital.unibarretos.net/index.php/Jurisbarretos/article/view/4/4. Acesso em: 11 maio 2016.

SOCIEDADE DA INFORMAÇÃO NO BRASIL. Sociedade da Informação; Mercado, Trabalho e oportunidades. Livro verde. Org. Tadao Takahashi. Brasília: Ministério da Ciência e Tecnologia, 2000. p.1-28. Disponível em: http://www.mct.gov.br/upd_blob/0004/4795.pdf . Acesso em: 11 mai. 2016.

SUPERIOR TRIBUNAL DE JUSTIÇA (STJ). Informativo $\mathbf{n}^{\mathbf{0}} 0528$ de 23 out. 2013. Brasília: Secretária de Jurisprudência do STJ, 2013. Disponível em: https://ww2.stj.jus.br/jurisprudencia/externo/informativo/?acao=pesquisarumaedicao\&livre= @ cod=0528. Acesso em: 10 mai. 2016. 